\title{
Development of a low cost Wireless Sensor Network for Surveillance along Kenya-Somalia Border
}

\author{
SIMON KARANJA HINGA \\ Hinga92@gmail.com
}

\begin{abstract}
Surveillance along the Kenya-Somalia border has been a big challenge that has continuously puzzled the security personnel, due to insurgency of armed militia Al-Shabaab from Somalia, the Kenyan government proposed construction of a barrier wall. This project developed a low cost wireless sensor network surveillance system to be deployed along the KenyaSomalia border. The research study utilized two PIR sensor for detecting human intrusion, one motion is detected the sensor transmit the data via an Xbee module. Arduino microcontroller was used to process the data collected by the sensor before transmission. The system developed has two units, the Transmitter unit and a User Graphic interface running on Tuna Term software that displays the received data. During testing, the prototype system detected human intrusion, using the Arduino serial monitor the results were displayed before being package for transmission.
\end{abstract}

\section{Keywords-Wireless Sensor network (WSN), Internet of Things (I.o.T)}

\section{INTRODUCTION}

A wireless sensor network is a set of miniature nodes that consume little energy and route information to a base station. Wireless sensor network that are deployed in applications such as battlefield monitoring and home sentry systems face acute security concerns, including eavesdropping, denial of service attacks and physical compromise of sensor nodes, Sensor networks offers the ability to monitor real-world phenomena in detail and at large scale by embedding wireless network of sensor nodes into the real world.

\subsection{Wireless Sensor Networks}

Wireless network is a kind of network, which includes many smart devices, called sensor nodes plus one or several sinks, randomly deployed in a wide area. These nodes are spatially distributed in order to perform an application-oriented global task. The basic component of the network is sensor. It is necessary for measuring real world physical conditions or variables such as humidity, pressure, temperature, vibration, pollutants, sound, motion and intensity, Such properties makes them to cover large areas of any geometry and one of the important design and implementation requirement of a typical sensor network is energy efficiency.

\author{
Badru, R. A.
}

Cooperative Information Network National

Space Research and Development Agency

Obafemi Awolowo University

Ile-Ife, NIGERIA

Wireless sensor networks are rapidly growing in popularity. Applications of sensor networks that have emerged include habitant monitoring (Mainwaring, Polastre, Sewezky, Culler, \& Aderson, 2002), robotic toys and battlefield monitoring. A wide range of application are emerging, including location aware sensor networks in the home and office, assistive technology for wearable biomedical sensing and monitoring, outdoor deployment of sensor network to monitor storms, oceans, and weather events, which perhaps realize the internet of Things (I.o.T) concept (Abderrahim Maizate \& Kamoun, 2013). The use of wireless sensor networks (WSN) does not require a specific infrastructure. But it poses a problem of scalability, energy conservation and connectivity over time, also wireless sensors can be exposed to highly dynamic and mobile environment, and therefore they must be fault tolerant nodes.

\subsection{History of Kenya-Somalia Trans-border Surveillance policy}

Due to constant insecurity as a of result trans-border immigration, the government of Kenya has begun to erect a barrier along its shared border with Somalia. Currently the construction work has being halted to pave way for negotiation between the two countries. This work looks at the interconnectedness of the Kenya-Somalia borderlands that are home to the Somali ethnic group as shown in figure 1.0 and the potential impact of the border barrier on this population. Although they are two nations separated by a clearly marked border, Kenya and Somalia are intimately connected by the Somali ethnic group that has long inhabited the lands lying on either side of the border

According to Mutisya (2017) the lack of governance in Somalia has led to the emergence of a clan-based insurgent and terrorist groupAl-Shabaab-and many years of instability have led to a large number of refugees and illegal immigrants in Kenya and other countries within the East African region. The refugees, illegal immigrants, and the Kenya Somalis form an extensive network for the Somali ethnic group within the region, which makes it easy for Al-Shabaab to recruit fighters from within this network. Mutisya (2017) research concludes that the barrier on the Kenya-Somalia border will impact the Somali ethnic group in the borderlands. To minimize this impact, the research recommends the border fence as a temporary solution to enhance security in Kenya and suggests ways for the government to leverage the support of the borderlands population to effectively ensure this solution.

While concluding Mutisya (2017) recommends: empowerment of young Kenyan Somalis at the Kenya-Somalia borderlands through job creation and economic investment to curb radicalization. Figure 
1.1 shows the Kenya-Somalia border overview map. My work aim at introducing a cost effective way of solving the security issue, by adopting a cost effective wireless sensor network which can cover the targeted areas effectively, while maintaining the Somali Clan heritage and protecting the communities that lives with the boarder.

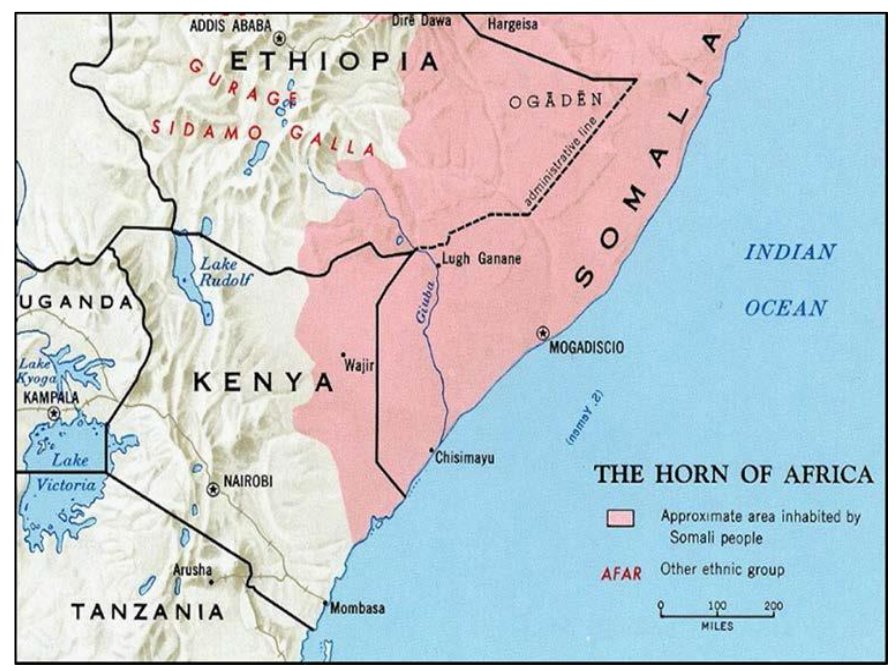

Figure 1.0. Area Occupied by the Somali Ethic Group ${ }^{1}$

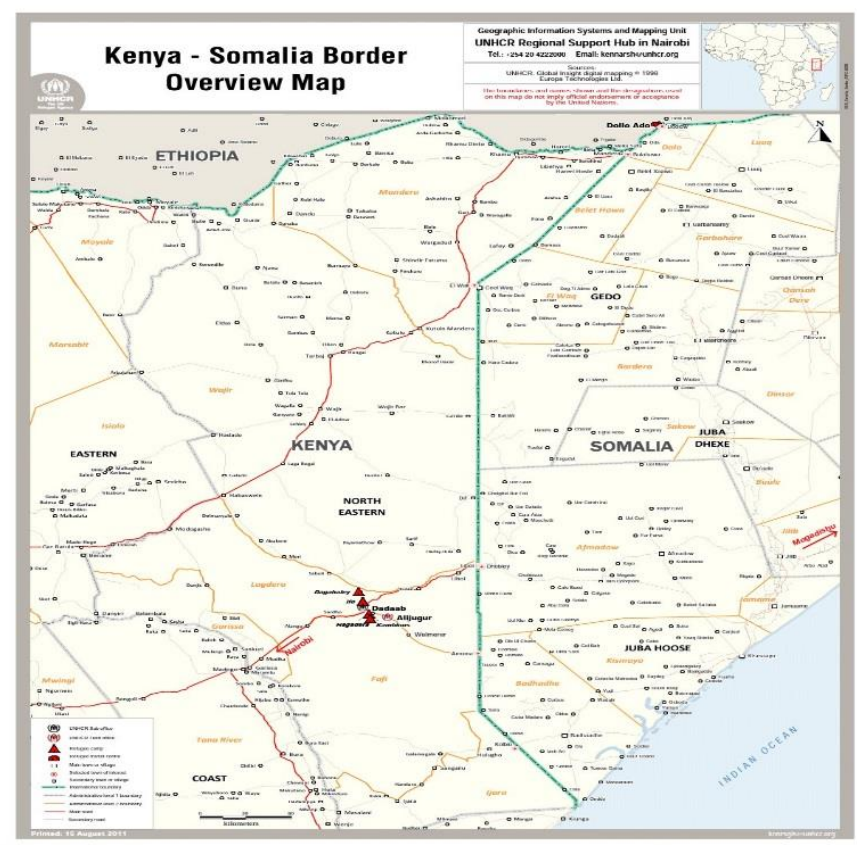

Figure 1.1 Map showing Kenya-Somalia boarder ${ }^{2}$

\section{METHODOLOGY}

\subsection{Design of a Wireless Sensor Network for Kenya-}

\section{Somalia Border}

This section gives the design of wireless sensor network for Kenya-Somalia border and provides the descriptive analysis of the hardware used in the implementation of this project. Since human intrusion can be detected using infrared emission from their body, PIR sensors will be used to detect the intrusion of human being around the border and the operation of the sensor will be integrated into microcontroller architecture. Following the detection of an intruder (human motion), the micro controller will send a short message (SMS) and email notification to the security personnel of human intrusion at the border. The microcontroller used for these work is Arduino Uno, HC 12 module will be used for sending data collected and intrusion report. A graphic user interface will be modelled and used at the base station to monitor the incoming data. The block diagram (showing the components) of the proposed system and its operational system and its operational flow chart is shown in figure 2.1 ( $a$ and $b$ )

2.2 Block diagram of the propose trans-border surveillance system

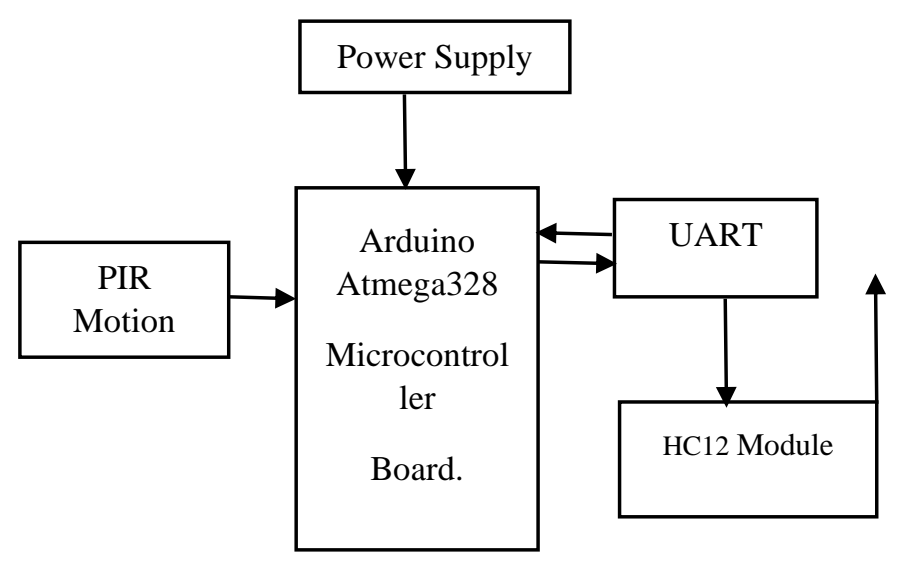

Figure 2.1 (a) Transmission section of the Trans-border surveillance

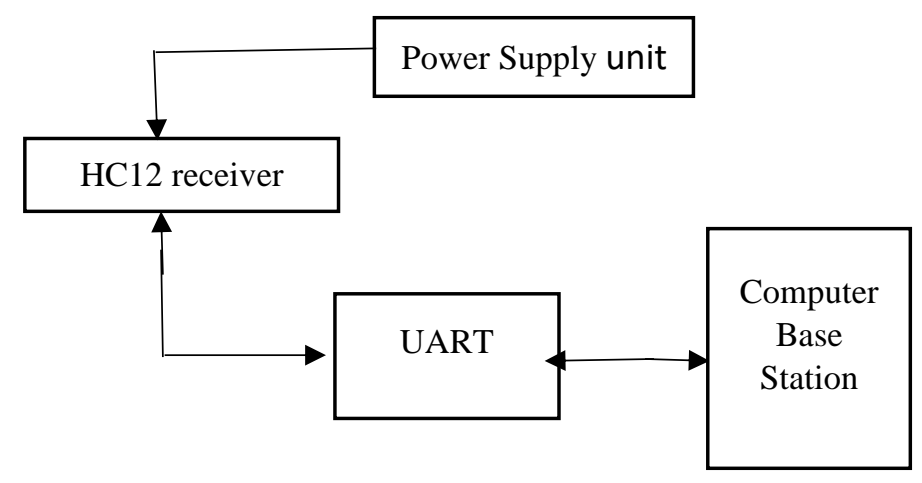

Figure 2.1(b) Receiver section of the trans-border surveillance system 


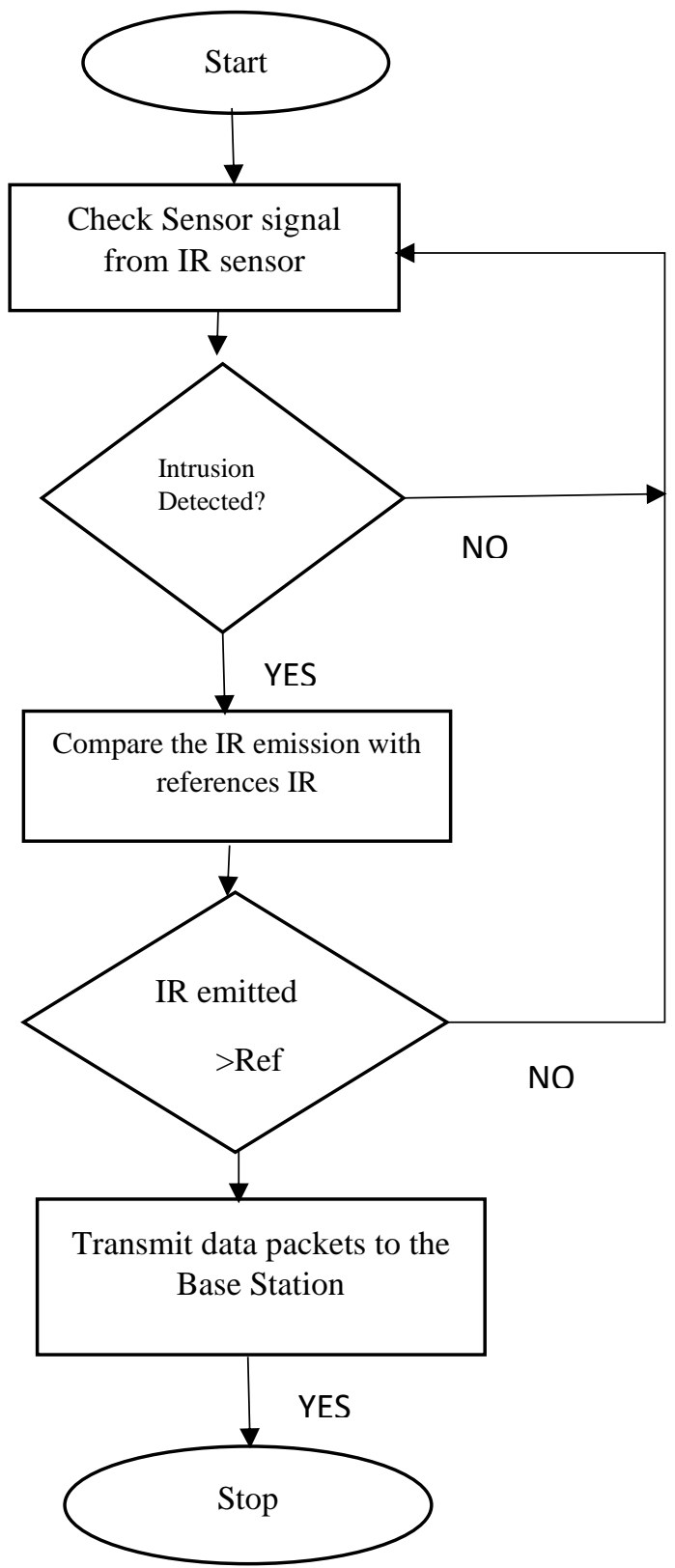

Figure 2.1(c) Flow chart of operation for the proposed transborder surveillance system

Figure 2.2 (a) and (b) shows design of the transceiver unit, the transmitter unit was modelled and implement as outlined in the block diagram, it consisted of power supply, Arduino microcontroller Atmega 328p, RED and green led, and two PIR sensors connected at 90 degrees and with a transmitter. After the design, the system performance was evaluated, below is a code snippet of the receiver unit used

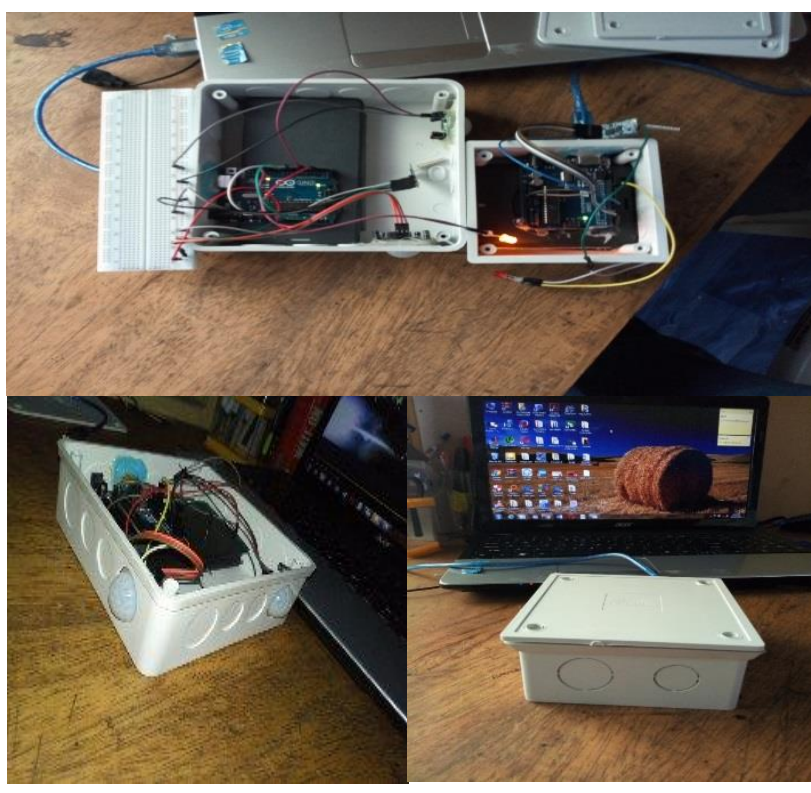

Figure 3.2 (a): Transmitter and receiver unit design work.

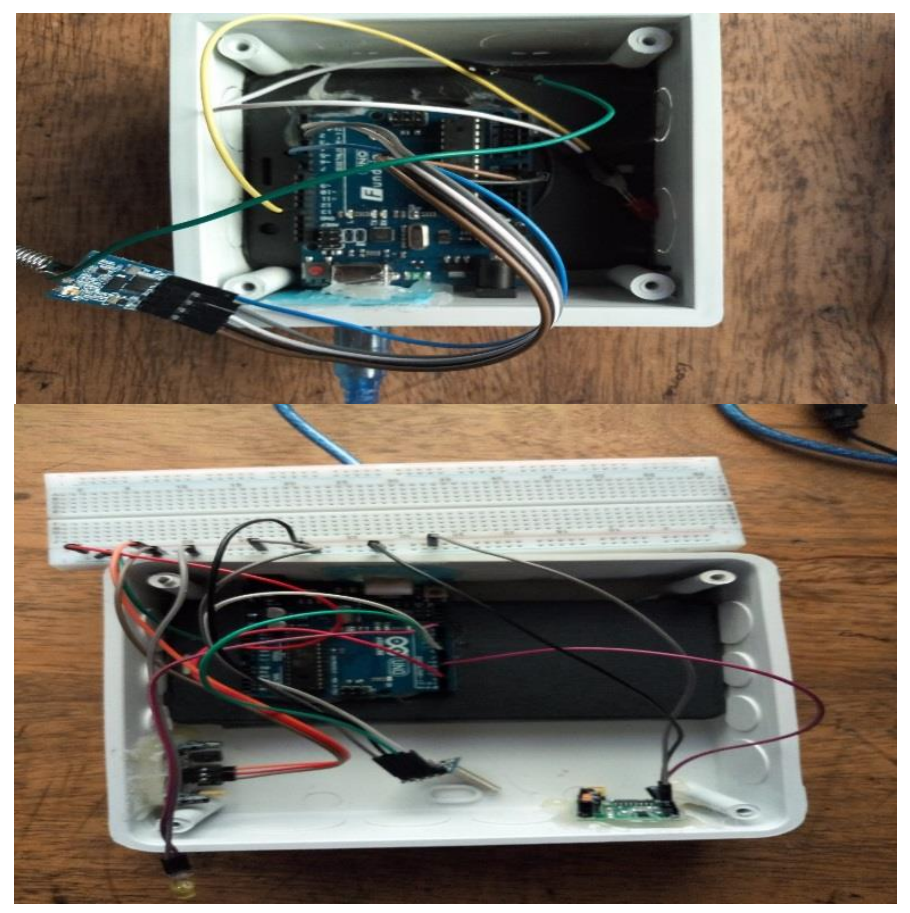

Figure 2.2(b): Receiver and transmitter evaluation

Figure 2.2 (c) shows the final prototype of the transceiver surveillance system designed, the code snippet below show the pins declaration used with one PIR sensor

\#include $\langle$ SoftwareSerial.h $\rangle$

\#include 〈Wire.h〉

int led = 13;

// the pin that the LED is atteched to int sensor $=2$; int state $=L O W$; int $\mathrm{val}=0$; char byteIn; // the pin that the sensor is atteched to // by default, no motion detected // variable to store the sensor status (value) // Temporary variable 
boolean serialEnd $=$ false;

String

String buffer2 = "";

HC12

\#define rxPin 8

\#define txPin 9

SoftwareSerial HC12(rxPin, txPin);// Rx of HC-12 to PIN 9 of the Arduino, TX of HC-12 of PIN 8 of the Arduino

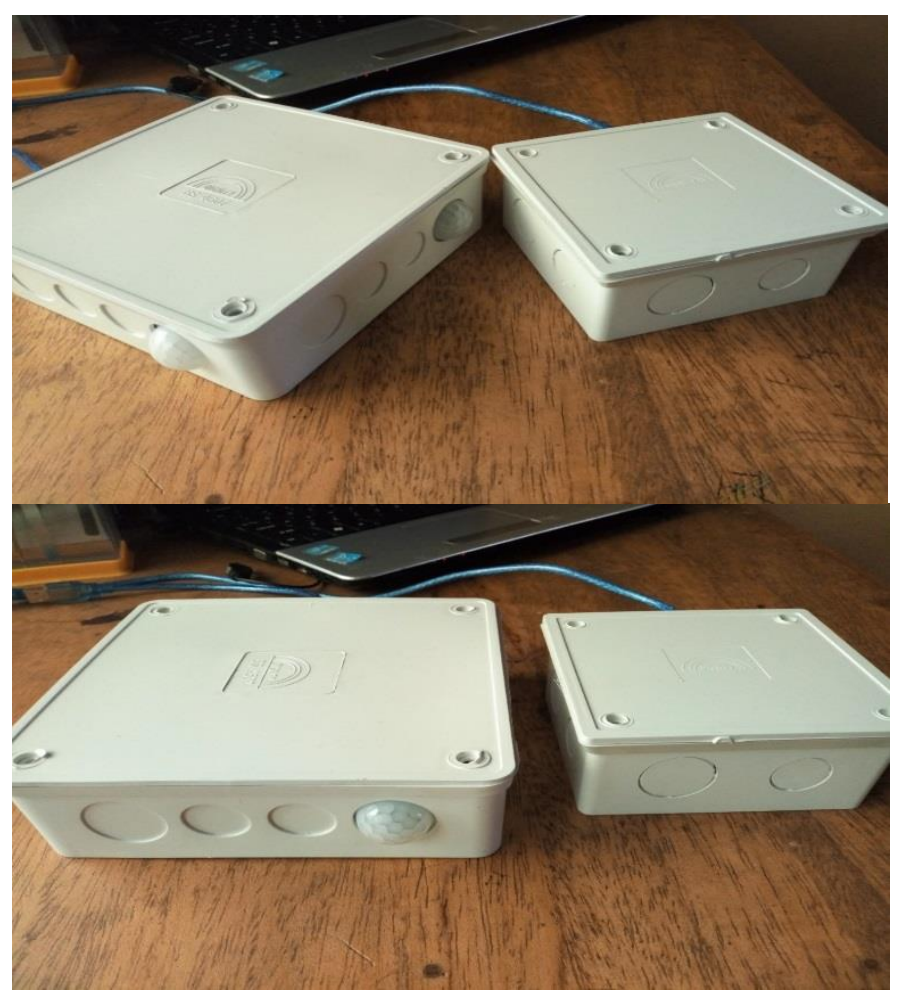

Figure 2.2 (c): Final prototype of the Transceiver surveillance system.

\section{RESULTS AND DISCUSSION.}

Figure 3.0 below shows the Arduino code used while coding the Atmega 328p Microcontroller, the code is $\mathrm{C}++$ written on the Arduino Integrated Development Environment (IDE), the code shows the programming steps used to code one PIR sensor when the motion is detected, in the code the sensor and led were declared as the main variable and assigned to pin 2 and 13 respectively. Then the PIR was set as INPUT and to work at a baud rate of $9600 \mathrm{bps}$ while the led was set as OUTPUT to display different state on the while the motion is detected. The sensor was set to low state initially to depict that no motion was detected when the sensor was not in operation.

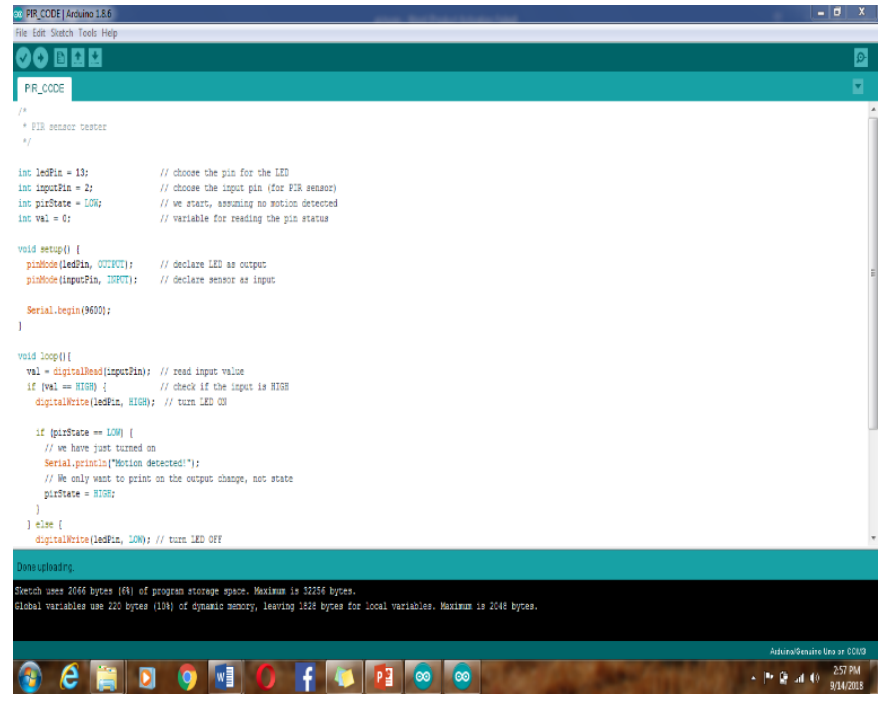

Figure 1.0 Arduino code for one PIR sensor

Figure 3.1 below shows the results obtained when motion is detected by the PIR sensor, the results are tabulated using Arduino serial monitor interface. At this stage the program was written to show when motion is detected and to display it by serial writing when there is motion. While the motion is detected, the connected LED at pin 13 Lights up to signify that motion is detected and remains on for a period of $200 \mathrm{~ms}$.



Figure 3.1 PIR results on Arduino serial monitor

While writing the code, a simulation test was done using Simulator for Arduino-(Free Version) version 1.06 (Delay=30S) designed by Virtronic (www.vitronic.com.au $)$, the figure 1.2 below shows the simulated results.

Using the Simulator, load the same code as used in the Arduino IDE, from the figure 3.2 shows the output at the Arduino when the declared INPUT is LOW, meaning that the sensor has not detected 
a motion. At this state, the Arduino digital pin is Low hence the LED is OFF.

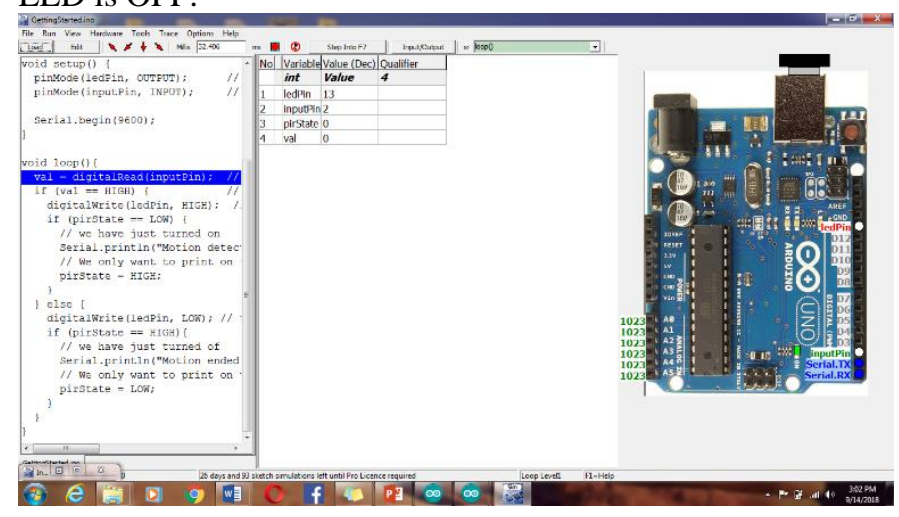

Figure 3.2 Simulated results at LOW State.

Simulation was done to show how the Sensor would behave when there was motion, figure 3.3 shows the sensor response when there was motion, the LED goes HIGH and a notification is printed in the serial monitor as shown in figure 1.1

On both simulations in figure 3.2 and figure 3.3, in both the transmitter pin and the receiver pin in Arduino simulator were both HIGH, this was set to ensure that at any given interval there was a serial transmission of received data.

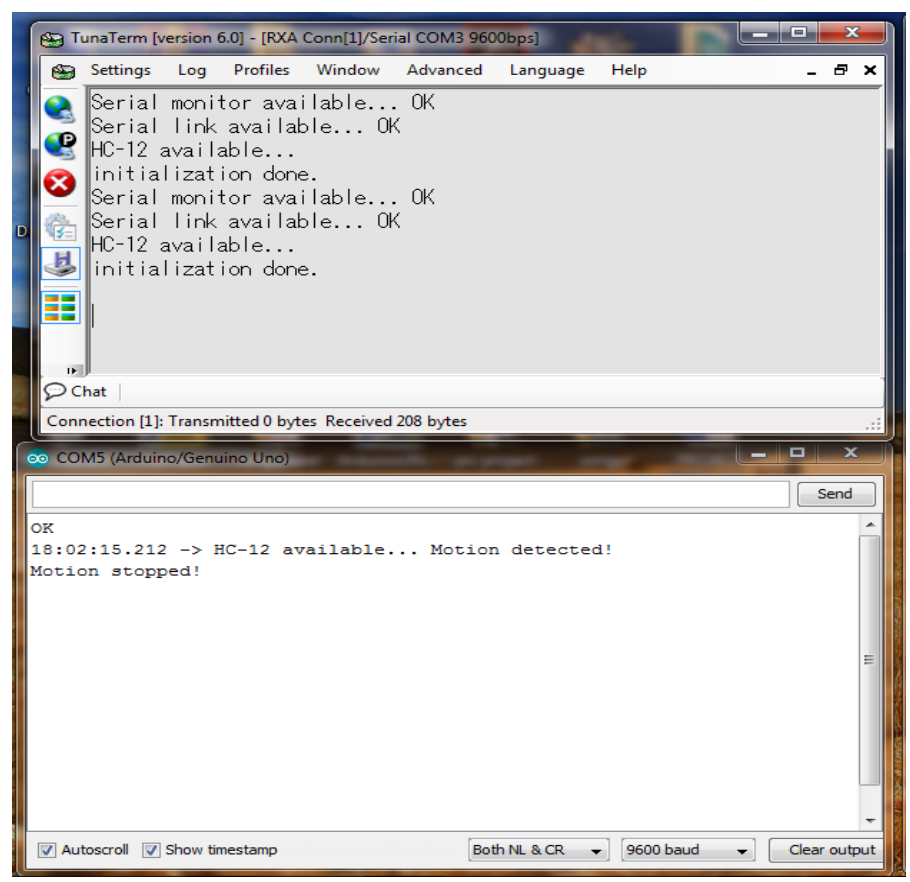

Figure 3.3 Tuna term interface- Base station interface.

\section{Result Discussion}

The prototype implemented is a low cost design using commercial off the shelf hardware, the results obtained from the sensor are a bit delayed, and as mentioned above the sensor have a range of operation within which it can be reliably triggered and transmit the data. The sensor are therefore suitable for the detection of human intrusion. The Arduino microcontroller transmission time is almost negligible since it only takes a few second to run through other process before sending results to the base station. The above system is a prototype of a system to be designed for real life application that would fit the desired deployment along the Kenya- Somalia border and achieve the objectives set forth.

\section{Research finding}

The results below show the sensor transmitting distance at an interval of $10 \mathrm{~cm}$, it's worth noting that the sensor response time was 3 seconds.

\begin{tabular}{|l|l|}
\hline $\begin{array}{l}\text { Distance between } \\
\text { transmitter antenna } \\
\text { and receiver antenna }\end{array}$ & $\begin{array}{l}\text { Time of } \\
\text { response for } \\
\text { PIR sensor }\end{array}$ \\
\hline $10 \mathrm{~cm}$ & $3 \mathrm{sec}$ \\
\hline $20 \mathrm{~cm}$ & $3 \mathrm{sec}$ \\
\hline $30 \mathrm{~cm}$ & $3 \mathrm{sec}$ \\
\hline $40 \mathrm{~cm}$ & $3 \mathrm{sec}$ \\
\hline $50 \mathrm{~cm}$ & $3 \mathrm{sec}$ \\
\hline $60 \mathrm{~cm}$ & $3 \mathrm{sec}$ \\
\hline $70 \mathrm{~cm}$ & $3 \mathrm{sec}$ \\
\hline $80 \mathrm{~cm}$ & $3 \mathrm{sec}$ \\
\hline $90 \mathrm{~cm}$ & $3 \mathrm{sec}$ \\
\hline $100 \mathrm{~cm}$ & 3 \\
\hline
\end{tabular}

\begin{tabular}{|l|l|}
\hline $\begin{array}{l}\text { Distance variation } \\
\text { interval }\end{array}$ & $\begin{array}{l}\text { Transmission } \\
\text { time }\end{array}$ \\
\hline $1 \mathrm{~m}$ & $3 \mathrm{sec}$ \\
\hline $2 \mathrm{~m}$ & $3 \mathrm{sec}$ \\
\hline $3 \mathrm{~m}$ & $3 \mathrm{sec}$ \\
\hline $4 \mathrm{~m}$ & $3 \mathrm{sec}$ \\
\hline $5 \mathrm{~m}$ & $3 \mathrm{sec}$ \\
\hline $6 \mathrm{~m}$ & $3 \mathrm{sec}$ \\
\hline $7 \mathrm{~m}$ & $3 \mathrm{sec}$ \\
\hline
\end{tabular}




\subsection{Conclusion}

This section gives the concluding remarks in this research study, the problems encountered as well as recommendations as to how improvements can be made in the nearest future. The project was focused on developing a security system that can be used to detect human intrusion along the Kenya-Somalia border, this wireless sensor are to be deployed and will be transmitting data in situ. The importance of the project, its achievement and limitations has been discussed earlier.

\subsection{Recommendations}

The system achieved the set objectives and performed perfectly, an area of possible improvement is integrating other sensing modalities like magnetic, thermal, acoustic, electric, seismic and optical which all forms a very concreate design of a robust system, also use of raspberry Pi board instead of Arduino microcontroller would improve on the transmission time and add memory capacity needed for more data enhancement technics, the use Raspberry Pi would guarantee data security as encryption and other forms of data security would be possible with a much better microcontroller

\section{Reference}

Abderrahim Maizate, \& Kamoun, N. E. (2013). "Passive Clustering for Efficient Energy Conversion in Wireless Sensor Network" International journal of Advanced Computer Science and Applications, vol 4(1).

Akyildiz, F., Sankarasubramaniam, Y., \& Cayirci, E. (2002). "Wireless sensor networks: a survey". Computer networks, vol. 38(no. 4), pp. 393.

Alanson, P., Daniel, Y., Pouline, S., \& Joshua, S. (2007, 24th Jan 2007). "Design of a Passively-Powered, programmable Sensing Platform for UHF RFID Systems". USA.

Arora, A., Dutta, P., kulathumani, V., Zhang, H., Naik, V., Mittal, v., . . Miyashita, M. (2004). " A line in the sand: a wireless sensor network for target detection, classification, and tracking". Computer networks, 46, 605-634. doi:10.1016

Baggio, A. (2005). Wireless sensor networks in precision agriculture,". Stockholm, Sweden.: in ACM Workshop on Real-World Wireless Sensor Networks (REALWSN 2005).
Dargie, W., \& poellabauer, C. (2010). Fundamentals of Wireless Sensor Networks Theory and Practice United Kingdom: A John Wiley and Sons, Ltd., Publication.

Deepali, J., Mohsin, M., Nandaanwar, S., \& Shingate, M. (2013). "Home Automation and Security System using Android ADK". international journal of Electronics and Computer Technology (IJECCT), vol 3(2).

Felisberto, P., Ricardo, C., \& Nuno, B. C. (2017). "Passive Sensors for Long Duration Internet of Things Network". doi: $10.3390 / \mathrm{s} 17102268$

Herring, C., \& Kaplan, S. (2000.). "Component-based software systems for smart environments,". IEEE Personal Communications, vol. 7( no. 5,), pp. $60\{61$.

Lady, A. (Producer). (2018, 06-07-2018). PIR Motion Sensor. Adafruit Learning system. Retrieved from www.learn.adafruits/pirpassive-infrared-proxmity-motion-sensor

Mainwaring, A., Polastre, R., Sewezky, D., Culler, J., \& Aderson, J. (2002). "wireless Sensor Network for habitant monitoring". First ACM Workshop on Wireless Sensor Network and Application (WSN), pp.88-97. 